\title{
Family planning need of people living with HIV/AIDS in antiretroviral therapy clinics of Horro Guduru Wollega zone, Ethiopia
}

\author{
Reta Tsegaye * (1)
}

\begin{abstract}
Objective: The purpose of this study was to identify factors associated with family planning needs among people living with human immunodeficiency virus (HIV) in Ethiopia.

Results: Three hundred twenty-one participants provided information on family planning methods and associated factors. Forty-six-point four percent of respondents reported using at least one form of family planning method; injectables (50.3\%) and condoms (70.2\%) were the most commonly used type of family planning method before and after HIV diagnosis, respectively. Age, the desire to have children, and the desire to have more than two children were significantly associated with the use of family planning methods.
\end{abstract}

Keywords: Family planning, People living with HIV (PLWH), Horro Guduru Wollega, Mother to child transmission

\section{Introduction}

By the end of 2015, the number of people living with HIV had reached an estimated 33.3 million. Women account for half of the estimated adults living with HIV and AIDS worldwide, the majority of whom are in their reproductive years $[1,2]$. With increased access to treatment for PLHIV, there has been a consequent decrease in mortality among PLHIV and subsequent increase in normal functioning including sexual activity [3].

Many women are at risk for unintended pregnancy and HIV infection at the same time. In a number of African countries the rate of unintended pregnancy among women living with HIV range from 51 to 84\% [4]. Family planning has a major impact on improving the overall health of a woman as well as that of her children by delaying first births, reducing the total number of children born to a woman, and preventing unintended pregnancies. Nearly one-third of maternal deaths could be prevented by meeting unmet need for family planning $[5,6]$.
Despite these benefits, in sub Saharan Africa, family planning among PLWH is not widely used [4]. A national survey conducted in Malawi among HIV positive women revealed that $51.2 \%$ of the respondents were using family planning methods and unmet need of FP methods were $21.9 \%$ [7]. According to a cross-sectional survey conducted in Tigray region, Ethiopia, $44.3 \%$ of the respondents were using contraceptive methods at time of survey [8]. A cross sectional study conducted in West Shewa zone, Ethiopia also revealed that less than half (43.1\%) of study participants were using family planning during the study period [9].

Factors associated with low utilization of family planning among PLWH vary across the countries and study sites. In the study area there is no available evidence on the use of family planning methods among PLWH. Thus, this study was done to explore factors associated with family planning needs among PLWH in Horro Guduru Wollega zone, Ethiopia.

*Correspondence: retatg@gmail.com

Department of Nursing and Midwifery, College of Health Sciences,

Wollega University, P.O. Box 395, Nekemte, Ethiopia 


\section{Main text \\ Methods \\ Study site}

The study was conducted in Horro Guduru Wollega (HGW) Zone, Oromia National Regional State. HGW is one of twenty zones of the region which has ten districts with different climatic conditions. This zone has a total population of 570,040 (285,515 male and 284,525 female) of which $11.36 \%$ of the population were urban inhabitants [10]. Shambu is the capital town of the zone and found $310 \mathrm{~km}$ from country's capital, Addis Ababa.

\section{Study population and design}

The study involved cross sectional institution based study among randomly selected PLWHA who were in reproductive age and had taken at least one visit at antiretroviral therapy (ART) care from the selected ART care unit from March 31 to April 30, 2012. There were ten health care institutions (one hospital and nine health centers) providing ART services in HGW Zone. Among these, one hospital and two health centers were randomly selected. The source population was all PLWH (men and women) following ART care unit in selected HGW zone ART care units during the study period. Study populations were randomly selected who were in reproductive age and had taken at least one visit at ART care from the selected ART care unit during the study period. Those who were critically ill and could not provide informed consent were excluded from the study.

\section{Sample size determination and sampling technique}

The sample size was determined using single population proportion formula taking the proportion of HIV positive individuals who received ART treatment and had the desire to have children is $40 \%$ from study done in Addis Ababa [11], 5\% marginal error, 95\% confidence interval. A total of 1050 eligible participants were identified. Since the total number of people living with HIV/ AIDS who were following ART clinics in HGW zone in ten ART clinics was $<10,000$, correction formula was used. To compensate the non-response rate, $10 \%$ of the determined sample was added up on the calculated sample size and the final sample size was 323 . Then the study participants were selected by systematic random sampling of every 3rd person from three study sites proportional their size. The dependent variable was family planning need, and the independent variables were sociodemography, fertility desire, and number of children desired.

\section{Data collection methods and tools}

Data was collected using structured questionnaire with closed and open ended questions. The questionnaire was adapted from different literatures [9, 11] (Additional file 1). The questionnaires were prepared in English, translated into Afan Oromo (working language of Oromia region), and then retranslated back to English by people who are proficient in both languages to maintain the consistency of the questionnaires. The questionnaire contained questions on socio-demographic characteristics, information about family planning use, choice and demand, and sexual behavior and condom use. Six data collectors were selected from the study site. Training was given for 2 days about the objective and relevance of the study, confidentiality of information, respondents' rights, informed consent and techniques of interview. Three supervisors were also selected from each site and closely followed the data collection process with principal investigator. Field questionnaires were reviewed each night and any issues encountered during data collection procedures were addressed accordingly.

\section{Data processing and analysis}

The data cleaning was done, entered into a computer by using EPI Info version 6.5. The data were then exported to SPSS windows version 20.0 for further analysis. The descriptive analyses such as proportions, percentages, frequency distribution and measures of central tendency were conducted. Bivariate analysis of demographic variables and family planning need was described. Odds ratio was used to check significant association between dependent and independent variables. Then all variables found to be significant at bivariate level ( $\mathrm{p}$ value $<0.05$ ) were entered into multivariate analysis using the logistic regression model to test the significance of the association.

\section{Results}

\section{Socio demographic characteristics of study participants}

Three hundred twenty-one respondents participated in the study among 323 eligible clients in the selected ARV care units, giving a response rate of $99.4 \%$. The majority $156(48.6 \%)$ of the respondents were between 30 and 39 years of age. The mean age (SD) of females and males were $31.4( \pm 5.8)$ and $35.6( \pm 7.9)$ respectively. The age range of the respondents was from 19 to 58 years. The majority more than half of the respondents were orthodox (51.4\%) in religion. Nearly one-third (29.65) of the study participants can't read and write (see Table 1 ).

\section{Family planning need, choice and use}

One hundred forty-nine (46.4\%) were using different types of family planning methods during the survey period. Among these $120(80.5 \%)$ and 50 (33.6\%) were using condom and injectables respectively. Out of those who were not using family planning method at the time 
Table 1 Socio demographic characteristics of respondents attending ART treatment units, Horro Guduru Wollega zone, Ethiopia, 2012

\begin{tabular}{|c|c|c|}
\hline Characteristics & Frequency & Percentage (\%) \\
\hline \multicolumn{3}{|l|}{ Age (years) } \\
\hline $18-29$ & 106 & 33 \\
\hline $30-39$ & 156 & 48.6 \\
\hline$\geq 40$ & 59 & 18.4 \\
\hline \multicolumn{3}{|l|}{ Sex } \\
\hline Female & 195 & 60.7 \\
\hline Male & 126 & 39.3 \\
\hline \multicolumn{3}{|l|}{ Religion } \\
\hline Orthodox & 165 & 51.4 \\
\hline Protestant & 136 & 42.4 \\
\hline Muslim & 13 & 4 \\
\hline Others & 7 & 2.2 \\
\hline \multicolumn{3}{|l|}{ Educational status } \\
\hline Can't read and write & 95 & 29.6 \\
\hline Read and write & 100 & 31.2 \\
\hline Primary & 57 & 17.7 \\
\hline Secondary & 52 & 16.2 \\
\hline Post secondary & 17 & 5.1 \\
\hline \multicolumn{3}{|l|}{ Ethnicity } \\
\hline Oromo & 272 & 84.7 \\
\hline Amhara & 45 & 14 \\
\hline Others $^{a}$ & 4 & 1.3 \\
\hline \multicolumn{3}{|l|}{ Marital status } \\
\hline Married & 186 & 57.9 \\
\hline Single/never married & 57 & 17.8 \\
\hline Widowed & 40 & 12.5 \\
\hline Divorced & 38 & 11.8 \\
\hline \multicolumn{3}{|l|}{ Occupation } \\
\hline House wife & 135 & 42.1 \\
\hline Farmer & 51 & 15.8 \\
\hline Daily laborers & 46 & 14.3 \\
\hline Government/private employee & 33 & 10.3 \\
\hline Jobless & 33 & 10.3 \\
\hline Merchants & 23 & 7.2 \\
\hline \multicolumn{3}{|l|}{ Income } \\
\hline No regular income & 126 & 39.3 \\
\hline$\leq 445$ & 147 & 46.0 \\
\hline$>445$ & 48 & 14.7 \\
\hline
\end{tabular}

a Guraghe, Tigre

of survey period, only 58 (33.7\%) of them have intended to use family planning methods in the future (Table 2).

\section{Sexual behavior and condom use}

One hundred ninety-six (61.1\%) of the study participants were sexually active within the past 6 months. Among these $128(65.3 \%)$ reported using condoms while 68
(34.7\%) did not use. Out of those who reported condom use, the majority 115 (89.8\%) used it regularly. The most common reason for condom use was advice from health professionals $57(44.5 \%)$ while wanting to have child 39 (57.3\%) was the most common reason for non condom use.

\section{Factors associated with family planning need}

From multivariate analysis, those ages group 18-29 were more likely want to use family planning methods than those above thirties (AOR: 2.5, 95\% CI 1.18-5.46). Study subjects who desired children were more likely to want to use family planning in the future than those who did not desire children (adjusted OR: 2.8, 95\% CI 1.2-6.6). On the other hand those who desired to have less than two children were less likely to use any family planning in the future than their counter parts (adjusted OR: 0.26, 95\% CI 0.1-0.8) (Table 3).

\section{Discussion}

The current study was undertaken to describe family planning need among people living with HIV/AIDS in Horro Guduru Wollega zone, Ethiopia. In this study about $44.5 \%$ of the respondents had used at least one method of family planning methods before HIV diagnosis and this number was increased to $57.6 \%$ after HIV diagnosis. This finding was similar with a study conducted among HIV positive women in South Gondar and North Wollo zone, Ethiopia and South Africa [12, 13]. The reason for increased utilization of family planning may be attributed to the counseling services they got from their ART providers to prevent unintended pregnancies and prevention of HIV re-infection from their partners. Among those who were not currently using, only $33.7 \%$ did want to use family planning in the future; indicating that counseling for family planning for these people still needs to be addressed.

Sixty-one point one percent of the study participants were sexually active 6 months preceding the survey. This finding was higher than study conducted in Bahir Dar city (50.4\%) of Ethiopia but lower compared to study conducted among serodiscordants in Henan, China (83.6\%) $[14,15]$. The increase in sexual activity among PLWH could be attributed to improved quality of life because of antiretroviral therapy, opportunistic infection prophylaxis and other health care packages [3]. With increased access to ART made possible by global and national initiatives, more HIV positive people are increasingly becoming healthier and more sexually active $[3,16]$.

Of those who were sexually active, the majority 128 (65.3\%) reported using condom while 68 (34.7\%) never used at all and among who reported using condoms, over $10 \%$ inconsistently used them. These findings were 
Table 2 Distributions of study participants by current use and future need of family planning methods in Horro Guduru Wollega zone, Ethiopia, 2012

\begin{tabular}{|c|c|c|}
\hline Contraceptive use $\mathrm{n}(\%)$ & Current use $\mathrm{n}(\%)$ & Future need to use $n(\%)^{a}$ \\
\hline Yes & $149(46.4)$ & $58(33.7)$ \\
\hline No & $172(53.6)$ & $114(66.3)$ \\
\hline Contraceptive methods & Current $^{\mathbf{b}}$ & Future $^{c}$ \\
\hline Injectables & $50(33.6)$ & $18(31)$ \\
\hline Condom & $120(80.5)$ & $31(53.4)$ \\
\hline OCPS & $5(3.3)$ & $4(6.9)$ \\
\hline Implants & $9(6)$ & $9(15.5)$ \\
\hline Others & $1(0.7)$ & $1(1.7)$ \\
\hline
\end{tabular}

a Among current contraceptive non users $(n=172)$

b Among current contraceptive users $(n=149)$ and more than one FP methods were reported use

c Among those who want to use contraceptive in the future $(n=58)$ and more than one FP methods were reported need in the future

Table 3 Association of future family planning need by selected variables among PLWH following ART unit, Horro Guduru Wollega zone, Ethiopia, 2012

\begin{tabular}{|c|c|c|c|c|}
\hline Characteristics & Need for future FP N (\%) & Do not need for future FP N (\%) & Crude OR $(95 \% \mathrm{Cl})$ & Adjusted OR $(95 \% \mathrm{Cl})$ \\
\hline \multicolumn{5}{|l|}{ Age } \\
\hline $18-29$ & $26(55.3)$ & $27(28.4)$ & $3.1(1.5,6.5)$ & $2.5(1.18,5.46)$ \\
\hline $30-39$ & $21(44.7)$ & $68(71.6)$ & 1 & 1 \\
\hline \multicolumn{5}{|l|}{ Sex } \\
\hline Male & $25(43.9)$ & $33(28.2)$ & $2(1.03,3.89)$ & $1.6(0.7,3.8)$ \\
\hline Female & $32(56.1)$ & $84(71.8)$ & 1 & 1 \\
\hline \multicolumn{5}{|l|}{ Marital status } \\
\hline Married & $25(43.9)$ & $40(34.2)$ & $1.5(0.8,2.9)$ & - \\
\hline Single/divorced/widowed & $32(56.1)$ & $77(65.8)$ & 1 & 1 \\
\hline \multicolumn{5}{|l|}{ Educational status } \\
\hline Illiterate/read and write & $38(66.7)$ & $80(68.4)$ & $0.9(0.5,1.8)$ & - \\
\hline Primary and above & $19(33.3)$ & $37(31.6)$ & 1 & \\
\hline \multicolumn{5}{|l|}{ Future child desire } \\
\hline Yes & $41(71.9)$ & $46(39.3)$ & $4(2.0,7.9)$ & $2.8(1.2,6.6)$ \\
\hline No & $16(28.1)$ & $71(60.7)$ & 1 & 1 \\
\hline \multicolumn{5}{|l|}{ Number of children desired } \\
\hline$\geq 2$ & $32(78)$ & $23(50)$ & $3.6(1.4,9.1)$ & $3.8(1.25,11.7) \mathrm{a}$ \\
\hline$<2$ & $9(22)$ & $23(50)$ & 1 & 1 \\
\hline
\end{tabular}

Italic shows significant association at $\mathrm{p}<0.05$

similar to study conducted in Malawi (65.8\%) and Nepal (65.8\%) reported condom use but lower compared to study conducted in Uganda (77.6\%) [17-19]. The results appear to indicate significant proportions of PLWH were increasingly practicing risky sexual behavior which has a greater risk of horizontal HIV transmission. So counseling regarding the importance of condom usage in conjunction with more effective modern contraceptive methods must continue to be reinforced over the course of ongoing ART treatment to prevent both infection and pregnancy. Oral pre-exposure prophylaxis (PrEP) for heterosexual HIV discordant couples has proven feasible to reduce HIV transmission and this may be considered as possible additional intervention for the uninfected partner [20].

This study identified many factors like age; desire to have children and number of children desired as important factors associated with future family planning need. Those who were age group between 18 and 29 were more likely to use family planning than those above thirties 
which was similar to study conducted in Uganda and Tigray region $[21,22]$. This may be attributed to the possible need of these populations to prevent unintended pregnancy, and delay to have children as their age is comparably younger than their counter parts. However, according to study conducted in Addis Ababa, age has no significant association with future family planning need.

The other factor associated with future family planning use was future desire for children. Those who desired children were three times more likely to use future family planning than those who did not desire children. Similarly study conducted in Addis Ababa, North Shewa (unpublished) and West Shewa zones of Ethiopia identified that those who desired children were more likely to use family planning in the future than their counter parts $[9,11]$. This may be again the possible need of these populations to limit and space the number of children. But according to study conducted in Kenyan health facility, those expressed fertility desire were less likely to use family planning in the future [23].

Number of children desired was another factor for future family planning need identified in this study; those who desired two and above children were more likely to use family planning methods than those who desired one. This may be again due to the possible desire of these populations to limit and space births as their desired number of children increases. This finding was comparable with the study conducted in slums of Nairobi, Tigray region and Debre Markos of Ethiopia [8, 24, 25] as respondents who have one or more living children were more likely to use contraceptive compared with those with no child.

\section{Limitation of the study}

- The cross-sectional nature of the data could not allow the causal effect relationships of dependent and independent factors.

- In this study, sexually active refers to sexual relationship between male and female only. Men sex with men (MSM) was not included as it is culturally inappropriate in the study area.

- Even though data collectors were trained on respondent's confidentiality, respondents may still provide desired answers by data collectors especially on sexual behaviors. Thus, social desirability bias may not be totally avoidable.

- Despite these limitations, the data being gathered possess a better description of family planning need of PLWH in the study area.

\section{Additional file}

Additional file 1. Questionnaire. Information sheets, Consent form and questionnaire used during the study.

\section{Abbreviations}

AIDS: acquired immune deficiency syndrome; ART: antiretroviral therapy; HGW: Horro Guduru Wollega; HIV: human immunodeficiency virus; PLWH: people living with HIV; SPSS: Statistical Packages for the Social Sciences.

\section{Acknowledgements}

I am grateful to acknowledge Addis Ababa University for funding this project. I would also like to acknowledge supervisors, data collectors, and study participants.

\section{Competing interests \\ The author declare that he has no competing interests.}

\section{Availability of data and materials}

All relevant data are within the manuscript.

\section{Consent for publication}

Not applicable.

\section{Ethics approval and consent to participate}

Ethical clearance was obtained from the Addis Ababa University Ethical Review Committee (Protocol No: 26/12/NURS). Permission was also obtained from Shambu Hospital, Wayu Health Center and Fincha Health Center by formal letter. Written informed consent was obtained from the study participants after telling purpose of the study and importance of their participation. The anonymity of the participants was respected by the use of codes rather than the name of the participants. The names of the participants were not reported in the findings of the study to ensure confidentiality.

Funding

This research was funded by Addis Ababa University.

\section{Publisher's Note}

Springer Nature remains neutral with regard to jurisdictional claims in published maps and institutional affiliations.

Received: 8 August 2017 Accepted: 3 November 2017

Published online: 09 November 2017

\section{References}

1. UNAIDS. Global AIDS update. Geneva: UNAIDS; 2016

2. WHO. Global health sectors strategy on HIV2016-2021 towards ending AIDS. Geneva: World Health Organisation; 2016.

3. Pearson CR, Kurth AE. Change in sexual activity 12 months after ART initiation among HIV-positive Mozambicans. AIDS Behav. 2012;15(4):778-87.

4. GBCHealth. Family planning and HIV services: increased efficiency and impact through integration. 2012. http://archive.gbchealth.org/asset/ family-planning-and-hiv-services-together-increase-efficiency-andimpact--issue-brief/. Accessed 16 Sept 2017.

5. UNAIDS/WHO. HIV and hormonal contraception: frequently asked questions. 2012. http://www.unaids.org/sites/default/files/media_asset/ JC2309_HIV_hormonal_contraception_en_0.pdf. Accessed 22 July 2017.

6. FHI360. Preventing unintended pregnancies and HIV. 2015. https:// www.fhi360.org/sites/default/files/media/documents/PMTCTbrief.pdf. Accessed 22 July 2017.

7. Habte D, Namasasu J. Family planning use among women living with HIV: knowing HIV positive status helps-results from a national survey. Reprod Health. 2015;12:1-11.

8. Melaku YA, Zeleke EG. Contraceptive utilization and associated factors among HIV positive women on chronic follow up care in Tigray Region, northern Ethiopia: a cross sectional study. PLOS ONE. 2014;9(4):1-10.

9. Ejeta $\mathrm{E}$, Abebe M. Fertility intention and family planning use among people living with HIV/AIDS in follow up care Western Shoa Zone (ART treatment unit). Am J Nurs Sci. 2009;2015(4):9-15. 
10. Federal Democratic Republic of Ethiopia population census commission. Summary and statistical report of 2007 population and housing census: population size by age and sex. Population Census Policy: Addis Ababa; 2008.

11. Tamene W, Fantahun M. Fertility desire and family-planning demand among HIV-positive women and men undergoing antiretroviral treatment in Addis Ababa, Ethiopia. Afr J AIDS Res. 2007;6(3):223-7.

12. Abeje G, Motbaynor A. Demand for family planning among HIV positive women on ART: the case of South Gondar and North Wollo Zones Amhara region. BMC Res Notes. 2016;9(43):1-6.

13. Oni EE, Ross A, Van der Linde S. Contraceptive practices amongst HIVpositive women on antiretroviral therapy attending an ART clinic in South Africa. Afr J Prim Health Care Fam Med. 2013;5(1):1-6.

14. Yalew E, Zegeye DT, Meseret S. Patterns of condom use and associated factors among adult HIV positive clients in North Western Ethiopia: a comparative cross sectional study. BMC Public Health. 2012;12:308.

15. Lu W, Zeng G, LUO J, Duo S. HIV transmission risk among serodiscordant couples: a retrospective study of former plasma donors in Henan, China. J Acquir Immune Defic Syndr. 2011;55(2):232-8.

16. Wilson TE, Gore ME, Greenblatt R, Cohen M, Minkoff H, Silver S, et al. Changes in sexual behavior among HIV-infected women after initiation of HAART. Am J Public Health. 2004;94(7):1141-6.

17. Haddad LB, Feldacker C, Jamieson DJ, Tweya H, Cwiak C, Chaweza T, et al. Pregnancy prevention and condom use practices among HIV-infected women on antiretroviral therapy seeking family planning in Lilongwe, Malawi. PLoS ONE. 2015;10(3):1-14.

18. Mishra SR, Joshi MP, Khanal V. Family planning knowledge and practice among people living with HIV in Nepal. PLoS ONE. 2014;9(2):1-8.

19. Musinguzi G, Bwayo D, Kiwanuka N, Coutinho S, Mukose A, Kabanda J, et al. Sexual behavior among persons living with HIV in Uganda: implications for policy and practice. PLOS ONE. 2014;9(1):1-10.
20. WHO. Guidance on pre-exposure oral prophylaxis for serodiscordant couples, men and transgender women who have sex with men at high risk of HIV. Geneva: WHO; 2012.

21. Kakaire O, Kaye DK, Osinde MO. Contraception among persons living HIV with infection attending an HIV care and support centre in Kabale, Uganda. J Public Health Epidemiol. 2010;2(8):180-8.

22. Berhane $Y$, Berhe $H$, Abera GB, Berhe $H$. Utilization of modern contraceptives among HIV positive reproductive age women in Tigray, Ethiopia: a cross sectional study. ISRN AIDS. 2013;2013:319724. http://dx.doi. org/10.1155/2013/319724.

23. Njuguna E, llovi S, Muiruri P, Mutai K, Kinuthia J, Njoroge P. Factors influencing the utilization of family planning services among HIV infected women in a Kenyan health facility. Int J Reprod Contracept Obstet Gynecol. 2017;6(5):1746-52.

24. Egzeabher SG, Bishaw MA, Tegegne TK, Boneya DJ. Modern family planning utilization and associated factors among HIV positive reproductive age women in Debre Markos Referral Hospital Northwest Ethiopia, 2014. Open J Epidemiol. 2015;5:32-40.

25. Wekesa E, Coast E. Contraceptive need and use among individuals with HIV/AIDS living in the slums of Nairobi, Kenya. Int J Gynecol Obstet. 2015;130:E31-6. https://doi.org/10.1016/j.ijgo.2015.05.001.

\section{Submit your next manuscript to BioMed Central and we will help you at every step:}

- We accept pre-submission inquiries

- Our selector tool helps you to find the most relevant journal

- We provide round the clock customer support

- Convenient online submission

- Thorough peer review

- Inclusion in PubMed and all major indexing services

- Maximum visibility for your research

Submit your manuscript at www.biomedcentral.com/submit
() Biomed Central 